\title{
Recent Advances of the Medicinal Plant Compound for Combating Pneumonia Disease: A Review
}

\author{
Megha Patel ${ }^{1}$, Bhavesh Sharma ${ }^{*}$ \\ ${ }^{1}$ C. G. Bhakta Institute of Biotechnology, Uka Tarsadia University, Maliba Campus, Bardoli-Mahuva Road, Tarsadi, 394350, Dist-Surat, Gujarat, India \\ ${ }^{2}$ Tarsadia Institute of Chemical Science, Uka Tarsadia University, Maliba Campus, Bardoli-Mahuva Road, Tarsadi, 394350, Dist-Surat, Gujarat, India
}

Correspondence to: Bhavesh Sharma, Tarsadia Institute of Chemical Science, Uka Tarsadia University, Maliba Campus, Bardoli-Mahuva Road, Tarsadi, 394350, DistSurat, Gujarat, India.

Received date: December 01, 2021; Accepted date: December 21, 2021; Published date: December 28, 2021

Citation: Patel M, Sharma B (2021) Recent Advances of the Medicinal Plant Compound for Combating Pneumonia Disease: A Review. J Med Res Surg 2(6): pp. 1-5. doi: $10.52916 / j m r s 214063$

Copyright: (C2021 Patel M, et al. This is an open-access article distributed under the terms of the Creative Commons Attribution License; which permits unrestricted use; distribution and reproduction in any medium; provided the original author and source are credited.

\section{ABSTRACT}

Bacteria, influenza, parasites and fungi are pathogenic microorganisms that cause infectious diseases. Diseases can spread from one individual to another, either directly or indirectly. Infectious diseases are world's second most common cause of death. Rainforest plants provide about quarter of drugs we need. Scientific research has been carried out on few medicinal plants, but only to small degree. Bacterial susceptibility to currently active antibiotics has necessitated discovery of new antibacterial agents. Several plants are widely used as herbal medicine for treatment of infectious diseases in rural and backward areas of India. This chapter looks over the publications on medicinal plants that are used to cure diseases like malaria, pneumonia. Traditional medicine is preferred primary health care system in many rural areas for variety of reasons, including its affordability and efficacy. The current study focused on existing medicinal plant literature, with ethnobotany, phytochemistry and pharmacology details being highlighted. All of examined plants showed potent action, supporting their conventional uses as well as their ability to cure common diseases. Curcuma longa L., Punica granatum L. and Justicia adhatoda L. were most widely used plant families for pneumonia therapy in research area (each with seven plants); of these, Curcuma longa L., Punica granatum L. and Justicia adhatoda L. had most inhibiting ability against Staphylococcus aureus and Streptococcus pneumoniae. Ascorbic acid, curcumin, vasicine, piperine, quercetin, myricetin and gallic acid have all been derived from these plants and are said to have antibacterial properties. Although Himalayan region has wide range of ethnomedicinal plants used to treat pneumonia, research on in-vivo activity, toxicology, and mechanism of action is minimal. As result, in order to produce novel antibacterial drugs from studied plant species, thorough study of these aspects is needed.

\section{Keywords:}

Antimicrobial Activity, Medicinal Plants, Pneumonia, Infectious Disease, Recent Advances

\section{Introduction}

Pneumonia is common respiratory illness that mostly affects lungs in humans. Streptococcus pneumoniae, Staphylococcus aureus, Klebsiella pneumoniae, Escherichia coli, Acinetobacter species and Pseudomonas aeruginosa are most prevalent pathogens causing community-acquired pneumonia worldwide; S. aureus and S. pneumoniae (pneumococcus) are most common pathogens causing community-acquired pneumonia worldwide. It is acute respiratory tract infection that induces inflammation in alveoli of lungs, resulting in pus and fluid deposition, making breathing difficult. Pneumonia is more common in younger children than in adults, causing 0.68-0.92 million deaths in children worldwide each year. Plants have long tradition being used to treat variety of human diseases. In addition to this problem, antibiotics have been linked to host side effects such as hypersensitivity, degradation of beneficial gut and mucosal microbes, immune suppression and allergic reactions. This has resulted in significant health challenge in management of infections. As result, substitute antimicrobial drugs for treatment of infectious diseases are needed; one strategy is to test local medicinal plants for antimicrobial properties. Plant materials are also valuable weapon in fight against dangerous diseases around world [1]. According to World Health Organization (WHO) (1993), herbal medicine is used by $80 \%$ of world's people and large portion of traditional therapies includes use of plant extracts or active constituents. However, scientific research into plant antimicrobial active compounds is relatively a recent area. Traditional medicinal methods, especially use of medicinal plants, continue to be important in meeting basic health needs of developing countries.

Various plant sections, such as leaf, stem, bark and root, are used to avoid, alleviate, or return anomalies to normal. Since use of "herbal treatments" does not specifically adhere to evidence gathered by experimental methods, traditional medicine considers "herbal drugs" to be unconventional medicine. Many prescription drugs commonly used by doctors, such as morphine, aspirin, digitalis, and quinine, have long tradition of use as herbal remedies. Active compounds isolated from higher 
plants are used in modern medicine and about $80 \%$ of these active ingredients provide strong association between their modern medicinal application and their conventional uses. In recent years, there has been growth in quest for and use of medications and dietary supplements derived from plants. Pharmacologists, microbiologists, botanists, and phytochemists are scouring globe for phytochemicals and signs that could lead to creation of medicines for variety of diseases [2]. As result, this thesis examined electronic database for medicinal plants with potent action in treating certain traditional and widespread ailments, such as pneumonia. Aim of this analysis was to compile scattered literature (ethnomedicines, in-vitro effectiveness, and phytochemistry) on Himalayan medicinal plants that have historically been used to treat pneumonia. There are many medicinal plant varieties, for example, that local people have historically used to treat respiratory tract infections such as pneumonia. However, literature on these medicinal plants is scattered in terms of ethnomedicinal use, phytochemical behaviour, and pharmacological activity. More specifically, there is little to no information on comparative analysis of identified Himalayan antipneumonial and antituberculosis plants, including phytocompounds, in vitro effectiveness, and toxicology. Comparative research on medicinal plants that have been mentioned would aid in discovery of new antipneumonial medicines. Furthermore, by establishing benchmark for future studies, this analysis will identify holes in current state of awareness [3].

\section{Antibacterial function of medicinal plants used to cure pneumonia}

54 medicinal plants have been recently screened for antibacterial action against $S$. aureus, while 12 plants have been examined against $S$. pneumoniae. Leaves, nuts, whole plants, stem bark, and rhizomes were most widely used plant sections in extract preparation using solvents such as $\mathrm{MeOH}$, $\mathrm{EtOH}$, and water. Because of their polar origin, ethanol and methanol are best solvents for extracting plants because they emit wide variety of bioactive compounds. Most popular strategies for detecting bacterial inhibition were disc diffusion and agar well diffusion. Disc diffusion process is most often used for antimicrobial susceptibility research [4]. Furthermore, agar well method and disc diffusion tests are low-cost, quick and easy to read and interpret. Plant extracts were officially tested in concentrations ranging from 0.005 to $10000 \mathrm{mg} / \mathrm{ml}$ and found to have clear inhibition zones ranging from 1 to $100 \mathrm{~mm}$ against bacterial pathogens which cause pneumonia with highest antibacterial activity ( $25 \mathrm{~mm}$ inhibition zones) that was found in aqueous extract of Cassia fistula $L$. at $0.32 \mathrm{mg} / \mathrm{ml}$ concentration against $S$. pneumoniae, while highest antibacterial activity (13.3 mm inhibition zones) was found in methanolic extract of Ampelocissus latifolia (Roxb.) Planch at $0.5 \mathrm{mg} / \mathrm{ml}$ concentration against $S$. aureus.

Minimum Inhibitory Concentration (MIC) values for $S$. aureus and S. pneumoniae were found to range between 0.0078 and $200 \mathrm{mg} / \mathrm{ml}$ in antibacterial sample on various extracts of medicinal plants commonly used to treat pneumonia. MIC was determined using variety of techniques including tube dilution, agar dilution, broth micro dilution, and serial tube dilution. Amounts of traditional drugs/antibiotics used as control for determining antibacterial efficacy is equivalent to MIC values of plant extracts and compounds. It is important to conduct clinical research on medicinal plants in order to produce new anti-pneumonia medicines with high effectiveness and little side effects. Herbal remedies are good source of variety of chemical compounds that can be used as starting point for manufacture of new anti-pneumonia drugs. Gallic acid, myricetin, quercetin, vasicine, piperine, ascorbic acid, 1,4-dioxan, pelargonidin-3-galactose, cyanidin-3-glucose, curcumin, bisdemethoxycurcumin, curcumin diglucoside, hexahydrocurcumin, and tetrahydrocurcumin have all been confirmed to have been isolated from A. J. latifolia, J. latifolia, J. Iatifolia, Adhatoda, Curcuma longa L., Bauhinia variegata Linn., Piper nigrum L., Adhato Punica granatum L. and Punica granatum $L$. Antibacterial behaviour was attributed to them [5]. Curcumin monoglucoside, curcumin analogue, inhibited $S$. aureus. Most pneumoniae is type of bacteria. Curcumin and its derivatives were shown to have more potent antibacterial action against $S$. pneumoniae strains. Because of its surfactant strength and structural resemblance to alkanols, gallic acid has best antibacterial action against $S$. aureus.

Similarly, phenolic compounds' optimum antibacterial potential is determined by their structures. Inhibition of enzymes, perhaps by reaction with sulfhydryl groups, or non-specific associations with proteins, which contributes with inactivation of protein activity, was believed to be responsible for phenolic toxicity to bacterial pathogens. Membrane-bound enzymes, cell wall polypeptides, and surface-exposed adhesions are all potential targets in bacterial cells. Phenols can also provide bacterial infections with substrates that are unavailable to them. Curcumin, most essential ingredient of Curcuma longa, which belongs to Zingiberaceae family and is commonly used in cooked food in Asia. It has wide range of pharmacological properties at relatively non-toxic levels [6]. Curcumin is made up of 20 different antibiotic compounds. It has been discovered to be effective against $S$. aureus and can one day be transformed as antibiotic. Most active phytochemical compounds isolated from leaves of $J$. adhatoda are stated to be vasicinone and vasicine. existence of these active compounds may explain why alcoholic extracts of this plant have strong antibacterial action against $S$. aureus. Piperine is compound found in black pepper (Piper nigrum) which shpwed antibacterial activity when combined with ciprofloxacin against Staphylococcus aureus, perhaps acting as efflux pump inhibitor. Secondary metabolites were found in Leucas aspera. pharmacological activities of link plant extracts against $S$. aureus are significant which may be because the plant extract is in a natural form, which contains higher concentration of bioactive compounds [7].

\section{Recent medicinal plants that have been shown to be effective against pneumonia}

Pneumonia is a respiratory tract infection that causes inflammation of one or both lungs due to fluid deposition in alveoli. Pneumonia may be moderate, extreme, or lifethreatening depending on whether it is caused by bacteria, viruses, or fungi. Streptococcus pneumoniae, most common cause, Staphylococcus aureus, Moraxella catarrhalis, Klebsiella pneumoniae, Haemophilus influenzae, Chlamydophila pneumonia and Legionella pneumophila may all cause bacterial 


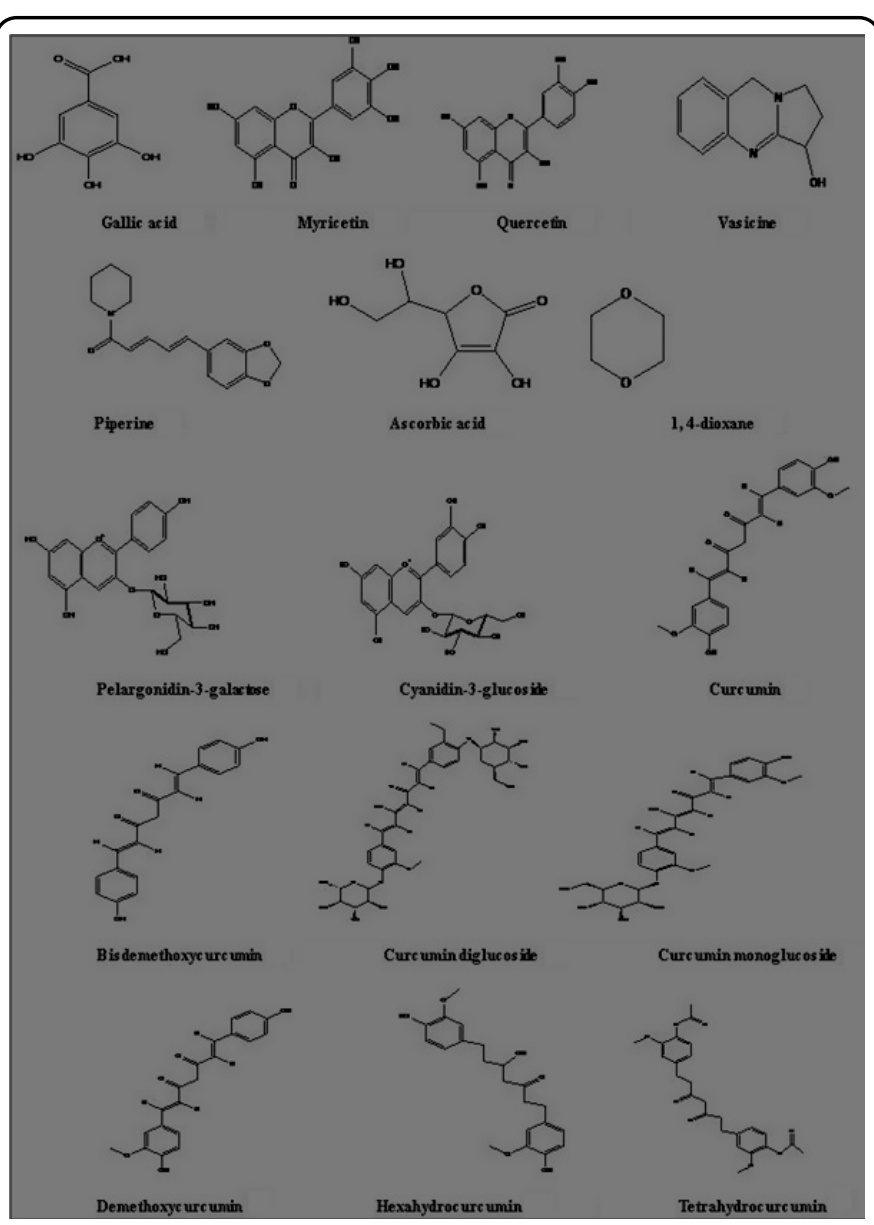

Figure 1: Chemical structures of antibacterial agents against S. pneumoniae and S. aureus.

pneumonia. Fungal pneumonia caused by Pneumocystis jirovecii is widespread in immunocompromised patients. Adenovirus, Varicella zoster, Influenza virus, and respiratory syncytial virus may all cause viral pneumonia. Medicinal plants have traditionally been used to cure pneumonia, necessitating scientific proof of their folkloric applications. Researchers have looked into such species, and following is summary of some of identified plants that have been seen to be active [8].

\section{Echinops adenocaulos}

Members of genus Echinops, which belongs to Asteraceae family, are used in Ethiopian herbal medicine to treat diarrhoea, intestinal worm infestation, haemorrhoids, migraine and other infections. With MIC of $0.781 \mathrm{mg} / \mathrm{mL}$, Zamzam water extract of E. adenocaulos showed antibacterial activity against multidrugresistant S. pneumoniae [9].

\section{Verbascum fruticulosum}

Because of its antibacterial action against Klebsiella pneumoniae and Staphylococcus aureus, several species of Verbascum (family Scrophulariaceae) have been used to treat pulmonary diseases in conventional medicine. antibacterial efficacy of $V$. fruticulosum aqueous extract against multidrug resistant clinical isolate of $S$. pneumoniae was high in vitro, with MIC value of $0.195 \mathrm{mg} / \mathrm{mL}[10]$.

\section{Parietaria judaica}

In herbal medicine, P. judaica, also known as pellitory of wall, is prized for its use as diuretic, balm for wounds and burns, and as soother for persistent cough. inhibitory effect of aqueous extract of $P$. Judaica was investigated using micro-broth dilution process. At MIC of $3.125 \mathrm{mg} / \mathrm{mL}$, extract was able to prevent multidrug-resistant S. pneumonia [11].

\section{Urtica urens}

The Urticaceae family's U. urens, also known as dwarf nettle or annual nettle, is used medicinally to treat pulmonary diseases. Using micro-broth dilution process, Saleh Fares et al. found MIC of $6.25 \mathrm{mg} / \mathrm{mL}$ for inhibitory action of aqueous extract of this plant against multidrug resistant clinical isolates of $S$. pneumoniae. This demonstrates potential for use as medication in treatment of multidrug-resistant S. pneumonia [12].

\section{Beta vulgaris}

$B$. vulgaris, also known as sugar beet, is sugar-producing plant in Amaranthaceae family. Sugar-producing plants produce bioactive compounds that are active against microbes and thereby protect sugar from fermenting or experiencing any changes. antimicrobial function of crude ethanolic leaf (lamina and midrib) extracts as well as fractions ( $n$-hexane and chloroform) against $K$. pneumonia was studied, and zones of growth inhibition were observed at various concentrations [13]. Lamina and midrib crude extracts had 19 and $9 \mathrm{~mm}$ inhibition zones, respectively, at $1 \mathrm{mg} / 12 \mu \mathrm{L}$. At concentration of $1 \mathrm{mg} / 6$ $\mu \mathrm{L}$, inhibition zones of chloroform lamina and midrib fraction were 12 and $14 \mathrm{~mm}$, respectively, while at concentration of 1 $\mathrm{mg} / 12 \mu \mathrm{L}$, they were 15 and $20 \mathrm{~mm}$. There were also 20 and 16 $\mathrm{mm}$ inhibition zones ( $1 \mathrm{mg} / 6 \mathrm{l})$ in $\mathrm{n}$-hexane lamina and midrib fractions, respectively, and 36 and $32 \mathrm{~mm}$ inhibition zones (1 $\mathrm{mg} / 12 \mathrm{l}$ ) in $\mathrm{n}$-hexane lamina and midrib fractions [14].

\section{Medicinal plant toxicity in treatment of pneumonia}

Just seven plants have been identified in this study to show toxic effects in humans and animals. People commonly believe ethnomedicinal plants are safe; however, harmful effects associated with use of herbal medicines have been identified. Toxic symptoms do exist, but they are mostly minor and affect only limited amount of individuals [15]. Glycyrrhizin has been shown to enhance adrenal cortex's hormone excretion in studies. When consumed at higher dosage, glycyrrhizinic acid, one of active ingredients in G. glabra, has been shown to have high toxicity, rendering it dangerous for patients with high blood pressure, renal failure, or heart disease. Owing to prolonged use, it also induces oedema and hypertension. $C$. longa contains number of active chemicals, including curcumin, which has antibacterial properties against S. aureus and S. Pneumonia [16]. When taken at $1000 \mathrm{mg} / \mathrm{kg}$, Hydro-Alcoholic Extract (HAE) of $C$. longa caused moderate toxicity such as depression, followed by initial excitements, reduced respiration, and dullness. $C$. longa HAE's curative dosage can be reduced to $500 \mathrm{mg} / \mathrm{kg}$. Furthermore, maximum concentration $(0.1 \mathrm{lg} / \mathrm{ml})$ of $C$. longa root extract applied to culture medium has negative effects on embryo. It halts growth of rabbit embryo at morula stage. At concentration of $150 \mathrm{~g} / \mathrm{ml}$, extract of Papaver somniferum $L$. causes necrosis in cells and is now considered good source of medication for many diseases [17].

\section{Conclusion}

The current research offers medicinal evidence for some of 
Table 1: Orthodox medicinal plants' toxicity in treatment of pneumonia.

\begin{tabular}{|c|c|c|c|c|c|c|}
\hline S. no & Plant name & Part used & Extract & $\begin{array}{l}\text { Concentration } \\
\text { (dose), } \mathrm{mg} / \mathrm{ml}\end{array}$ & $\begin{array}{l}\text { Examined } \\
\text { animal }\end{array}$ & Toxic effects \\
\hline 1 & Acorus calamus L. & Rhizome & Acetone & 100 & Sheep & Haemolysis \\
\hline 2 & $\begin{array}{c}\text { Aloe vera (L.) Burm.f } \\
\text { (=Aloe barbadensis Mill.) }\end{array}$ & Leaves & Hydro ethanol & 3.2 & Human & $\begin{array}{l}\text { MRC-5 human fetal lung } \\
\text { fibroblast cell line }\end{array}$ \\
\hline \multirow[t]{2}{*}{3} & \multirow[t]{2}{*}{ Curcuma longa L. } & Rhizome & Hydro alcohol & 1000 & Rat & $\begin{array}{l}\text { Mild depression, reduced } \\
\text { respiration, dullness }\end{array}$ \\
\hline & & Root & Root extract & 0.1 & Rabbit & $\begin{array}{l}\text { Terminates embryo de- } \\
\text { velopment at the morula } \\
\text { stage, apoptosis }\end{array}$ \\
\hline 4 & $\begin{array}{c}\text { Ephedra gerardiana } \\
\text { Wall. ex Stapf }\end{array}$ & Herb & Alkaloid & Excess amount & Human & $\begin{array}{l}\text { Liver damage, high blood } \\
\text { pressure, heart problem }\end{array}$ \\
\hline \multirow[t]{2}{*}{5} & \multirow[t]{2}{*}{ Glycyrrhiza glabra L. } & Root & $\begin{array}{l}\text { Glycyrrhizinic } \\
\text { acid }\end{array}$ & Excess amount & Human & $\begin{array}{l}\text { Blood pressure, kidney, } \\
\text { oedema and hypertension }\end{array}$ \\
\hline & & Dried root & $\begin{array}{l}\text { Glycyrrhizinic } \\
\text { acid }\end{array}$ & $760-2,280$ & Human & Hypokalemia, oedema \\
\hline \multirow{4}{*}{6} & \multirow{4}{*}{$\begin{array}{l}\text { Hygrophila auriculata } \\
\text { (Schumach.) Heine }\end{array}$} & Seed & Gentamicin & 80 & \multirow{3}{*}{$\begin{array}{l}\text { Human cancer } \\
\text { cell lines } \\
\text { (Breast, Colon) }\end{array}$} & \multirow{3}{*}{ Cytotoxicity } \\
\hline & & & Methanol & $1.1-1.6$ & & \\
\hline & & & Aqueous & 0.22 & & \\
\hline & & Leaves & $\begin{array}{c}\text { Methanolic } \\
\text { extract }\end{array}$ & 2000 & Albino rat & Dehydration \\
\hline
\end{tabular}

Himalayan regions historically used antipneumonial species, and is one of world's most diverse regions. Leaves are most active plant component used in recipe formulations for treatment of both diseases, and they have shown to be very successful. As result, each portion of plant must be carefully examined prior to extraction and recipe formulation. Most ethnomedicinal data from Himalayan studies is lacking, including approved botanical names, parts used, quantitative recipe dosage, dosage range (children, adults), recovery time, and side effects. Both of plants examined showed significant activity, confirming their numerous conventional uses as well as their ability to cure common diseases. As result, further research into these plants is needed, including isolating active compounds that can be converted into novel and potent drugs, as well as studying their modes of action. To have full information on each plant species used to treat both diseases, comprehensive ethnomedicinal studies should be conducted. antibacterial efficacy of number of commonly used medicinal plants from Himalaya area has been examined in vitro. Because of shortage of laboratory facilities or other factors, majority of research concentrated on antibacterial action of plants against pathogens that cause pneumonia. Similarly, less plant extracts and isolated compounds have been examined in vitro for in vitro validity and mode of action against pathogens that cause pneumonia. In known Himalayan medicinal plants, different groups of compounds (alkaloids, flavonoids, phenolics, and terpenoids) exist; however, only few compounds have been isolated and examined in vitro against bacterial pathogens. Certain compounds isolated from J. Adhatoda, A. latifolia, C. longa, $P$. granatum, and $P$. nigrum, such as ascorbic acid, gallic acid, quercetin, myricetin, curcumin and its derivatives, cyanidin3-glucoside, pelargonidin-3-galactose, vasicine, and piperine, have been found to be very active. In general, there is paucity of information on separation of pure and active compounds with anti-S. aureus and anti-S. pneumoniae action that may contribute to production of medications. As result, further emphasis can be placed on discovery of new antibacterial substances from previously unexplored plants. Majority of plant extracts and compounds have lower inhibitory concentrations than normal drugs/antibiotics, according to findings. It suggests that these plants have ability to be effective antibacterial agents.

\section{Funding}

None

\section{Conflict of Interest}

The authors declared no conflict of interest for this study.

\section{References}

1. Rabie H, Goussard P (2016) Tuberculosis and pneumonia in HIV infected children: overview. Pneumonia 8: pp. 1-10.

2. WHO (2008) Global tuberculosis control: Surveillance, planning and financing, WHO report. Geneva, Switzerland.

3. Marais BJ, Pai M (2007) Recent advances in diagnosis of childhood tuberculosis. Arch Dis Child 92: pp. 446-452.

4. Tariq A, Mussarat S, Adnan M (2015) Review on ethnomedicinal, phytochemical and pharmacological evidence of Himalayan anticancer plant. J Ethnopharmacol 64: pp. 96119.

5. Shah A, Rahim S, Bhatti K, et al. (2015) Ethnobotanical study and conservation status of trees in district Sargodha, Punjab, Pakistan. Int J Exp Bot 84: pp. 34-44.

6. Hasan A, Md. Shaown SH, Ripa RJ, et al. (2013) Ethnomedicinal plants of two villages in Natore district, Bangladesh. Am Eurasian J Agric Environ Sci 7: pp. 282-289.

7. Kumar RS, Sivakumar T, Sundaram RS, et al. (2006) 
Antimicrobial and antioxidant activities of Careya arborea Roxb stem bark. Iran J Pharmacol Ther 5: pp. 35-41.

8. Magaldi S, Mata-Essayag S, Hartung de Capriles C, et al. (2004) Well diffusion for antifungal susceptibility testing. Int J Infect Dis 8: pp. 39-45.

9. Roshan A, Verma NK, Kumar CS, et al. (2012) Phytochemical constituents, pharmacological activities and medicinal uses through millenia of Glycyrrhiza glabra review. Int Res J Pharm 3: pp. 45-55.

10. Govind P (2011) Active principles and median lethal dose of Curcuma longa Linn. Int J Res Pharm 2: pp. 239-241.

11. Foldesiova M, Balazi A, Chrenek P (2016) The effect of Curcuma longa plant extract on rabbit embryo development in vitro. Slovak J Anim Sci 49: pp. 132-136.

12. http:// www.iarc.fr/en/publications/books/wc r/wcrorder. php.
13. Sharma A, Kumar A (2016) Antimicrobial activity of Justicia adhatoda. World J Pharm Sci 5: pp. 1332-1341.

14. Pa R, Linu M (2012) Antimicrobial activity of leaf extracts of Justicia adhatoda L. in comparison with vasicine. Asia Pac J Trop Biomed 2: S1556-S1560.

15. Bagavan A, Rahuman AA, Kaushik NK, et al. (2011) In vitro antimalarial activity of medicinal plant extracts against Plasmodium falciparum. Parasitol Res 108(1): pp. 15-22.

16. Mittal M, Gupta N, Parashar P, et al. (2014) Phytochemical evaluation and pharmacological activity of Syzygium aromaticum: comprehensive review. Int J Pharm Pharmaceutic Scie 6(8): pp. 67-72.

17. Ichino C, Soonthornchareonnon N, Chuakul W, et al. (2006) Screening of Thai medicinal plant extracts and their active constituents for in vitro antimalarial activity. Phytotherapy Res 20(4): pp. 307-309. 